\title{
The Effect of Non-Supervised Physical Activity Before and After Breast Cancer Surgery on Quality of Life; Follow-Up Results From a Randomised Controlled Trial (Physsurg-b)
}

Jenny Eva Maria Heiman ( $\square$ jenny.heiman@vgregion.se)

Sahlgrenska universitetssjukhuset Verksamhet Kirurgi Sahlgrenska https://orcid.org/0000-0003-15927354

\section{Aron Onerup}

Sahlgrenska University Hospital: Sahlgrenska universitetssjukhuset

David Bock

Scandinavian Surgical Outcomes Research Group

\section{Eva Haglind}

Sahlgrenska University Hospital: Sahlgrenska universitetssjukhuset

\section{Roger Olofsson Bagge}

Sahlgrenska University Hospital: Sahlgrenska universitetssjukhuset

\section{Research Article}

Keywords: Breast cancer, Surgery, Physical activity, Prehabilitation, Quality of Life

Posted Date: February 8th, 2021

DOl: https://doi.org/10.21203/rs.3.rs-172101/v1

License: (c) (1) This work is licensed under a Creative Commons Attribution 4.0 International License.

Read Full License 


\section{Abstract}

Purpose

We conducted a randomised controlled trial (PhysSURG-B) to assess the short- and long-term effects of a non-supervised physical activity intervention at the time of breast cancer surgery. Here we report a secondary outcome, quality of life (QoL).

Methods

Female patients planned for surgery were randomly assigned to either an intervention of 30 minutes of self-administered physical aerobic activity daily 2 weeks before and 4 weeks after surgery, or control. QoL was assessed with questionnaires at baseline, 4 weeks and 12 months postop using the instruments FACT-B, RAND-36 and EQ-VAS.

Results

Out of 354 included participants at 12 months follow-up after surgery, 287 were available for QoL analysis. Comparing intervention to control, the results for the FACT- B score at 4 weeks showed an odds ratio (OR) of $0.975(95 \% \mathrm{Cl} 0.636-1.495)$ and at 12 months an OR of 0.883 (95\% $\mathrm{Cl} 0.581-1.342)$. The subgroup of patients receiving adjuvant chemotherapy had significantly lower FACT-B at 12 months compared to no chemotherapy (OR 0.475, 95\% Cl 0.300-0.735). EQ-VAS showed OR 1.163 ( $95 \% \mathrm{Cl} 0.760$ 1.779) and 0.817 (95\% $\mathrm{Cl} 0.536-1.244)$ at 4 weeks and 12 months, respectively. RAND-36 domains "role limitations due to physical health" and "pain" showed a decrease at 4 weeks in both groups, returning towards baseline at 12 months follow-up.

Conclusion

An intervention of non-supervised physical activity before and after surgery for breast cancer had no effect on QoL. Patients receiving adjuvant chemotherapy had significantly lower QoL, regardless of study group.

Trial registration

ClinicalTrials.gov registration number: NCT 02560662. Registered 25 September, 2015.

\section{Background}

Breast cancer affects more than 1.6 million women worldwide every year [1]. Following treatment, common side-effects are known to have negative impact on survivorship [2]. For proper management of patients, evaluating the effect of breast cancer treatment on survivorship is crucial [2]. Patient-reported outcomes (PROs) [3-5], such as quality of life (QoL), are especially important to assess $[4,5]$. 
In observational studies, regular physical activity after breast cancer diagnosis has been associated with increased breast cancer-specific and overall survival [6-8]. In patients undergoing adjuvant treatment for breast cancer, interventions with physical exercise during or after treatment have been reported to reduce fatigue [9-11] and to increase QoL [12-15]. To our knowledge, there are no reports of large randomized trials of prehabilitation consisting of physical activity before breast cancer surgery which address shortand long-term QoL.

\section{Methods}

\section{Aim}

The aim of this study was to evaluate the effects on a secondary outcome, quality of life, of a selfadministered intervention with pre- and postoperative physical activity compared with a control group, within 12 months after primary breast cancer surgery.

\section{Study design and setting}

We report 4 weeks and 12 months follow-up data from the PhysSURG-B randomised, controlled, prospective interventional trial evaluating an intervention of added aerobic physical activity before and after breast cancer surgery. The study protocol and primary outcome of self-reported physical recovery at 4 weeks after surgery have been published elsewhere [16]. Participants were recruited from three surgical departments in the Western Region of Sweden between Nov 2016 and Dec 2018. Participants were randomised to intervention with non-supervised physical activity, or control.

\section{Participants and randomisation}

Female patients $\geq 18$ years, diagnosed with stage I-III breast cancer, scheduled for primary surgery were randomised into two groups, intervention and control. Exclusion criteria were male sex, stage IV disease, neoadjuvant treatment and inability to understand the study information or perform the intervention. Neither research nurses or participants were blinded, due to the nature of the intervention, but patient allocation was not actively briefed to healthcare personnel involved in the routine care of the patient.

\section{Intervention and control}

- The intervention in the PhysSURG-B trial has been described previously in detail [16]. In summary, patients in the intervention group received an individual consultation with a physiotherapist and were instructed to add 30 minutes of daily aerobic physical activity, 2 weeks \pm 1 week before and 4 weeks after breast cancer surgery. The intervention was instructed to be of medium intensity resulting in shortness of breath but with ability to talk, of the participant's own choice after suggestions from the physiotherapist, and to be performed without supervision. In addition, two follow-up telephone calls were made during the intervention period. Added physical activity was registered in a diary. Adherence to the intervention was considered if registered physical activity was $>10$ days preoperatively and $>20$ postoperatively. 
- Participants in the control group were not advised regarding physical activity, but received standard information regarding early mobilization and shoulder movement after surgery according to standard care.

- The level of physical activity was measured with the Saltin Grimby Physical Activity Level Scale (SGPALS) [17].

\section{Outcome measures}

Patient-reported outcome measures of quality of life was a secondary outcome in the PhysSURG-B-trial, reported at three time points from which change from baseline to 4 weeks and 12 months respectively after surgery was calculated. The following validated instruments were used (Swedish versions):

- Functional Assessment of Cancer Therapy-Breast Cancer (FACT-B) [18], including FACT-B Total Score, FACT General (FACT-G) Total Score and FACT-B Trial Outcome Index (TOI).

- RAND 36-Item Health Survey 1.0 [19]

- EuroQol- visual analogue scale (EQ-VAS) [20]

- A single-item QoL question validated and used previously [21-23] asking "How would you describe your quality of life the last month?" Answering alternatives on a scale from "0" (worst possible quality of life) to "6" (best possible quality of life).

\section{Sample size and statistical analysis}

The sample size calculation for PhysSurg-B was performed for the primary outcome measure of physical recovery 4 weeks after surgery. No sample size calculation was performed for the secondary outcome quality of life.

A statistical analysis plan was written before any of the analyses were performed. The analyses were according to randomisation (intention-to-treat analysis). Baseline demographic data (patient and tumour characteristics and type of surgery) were described per allocated group. Total scores and subscale scores of the QoL instruments were calculated. The scores (total score for FACT-B, EQ-VAS) had skewed and multi-modal distribution making a gaussian linear model invalid. Therefore, the effect of the intervention was estimated using an ordinal regression model [24]. The baseline measurements were included as a covariate along with fixed factors for study group, time and their interaction. The single item QoL question was dichotomised into "low QoL" (scale option 1-4) and "high QoL" (scale option 5-6) before analysis. For all instruments, the primary analysis was the unadjusted. Adjuvant chemotherapy was imbalanced across the study groups and therefore, as an additional analysis adjuvant chemotherapy was adjusted for. Also, a subgroup analysis of patients given adjuvant chemotherapy was conducted.

The results are presented as odds ratios (OR) for intervention scoring higher than the control with $95 \%$ confidence intervals (Cls). All tests were two-sided and a statistical significance level of $5 \%$ was used. We 
made no adjustments for multiple comparisons. No imputations were made. All statistical analyses were performed with SAS $\rightarrow$ 9.4.

\section{Ethics}

The Regional ethical review board in Gothenburg, Sweden approved the trial (registration numbers 522 $15, T 1152-16, T 700-17, T 160-18)$. The procedures used in this study adhere to the tenets of the 1964 Helsinki declaration with amendments. Informed consent was obtained from all individual participants included in the study. PhysSURG-B was registered at ClinicalTrials.gov (NCT 02560662) September 25, 2015.

\section{Results}

The participant flow throughout the trial is visualised in Fig. 1. At 12 months after surgery 354/400 participants $(88.5 \%)$ remained in the trial, 44 patients withdrew informed consent (18 in the control group and 26 in the intervention group) and one participant in each group had died. 297/354 (84\%) returned their questionnaires (return rate $83-90 \%$ for the different timepoints), with no difference between the study groups. Complete data for QoL assessment at all three time-points was reported by $81 \%(287 / 354$ participants), 148 in the control group and 139 in the intervention group respectively.

Baseline patient demographics, tumour characteristics and type of surgery were similar in the two study groups (Table 1 and Table 2). Median age was 63 years (mean 62 years, range 30-89 years). More than thirty percent of the participants reported a risk consumption of alcohol according to Alcohol Use Disorders Identification Test (AUDIT-C), and two thirds of the patients had at least one comorbidity where cardio-vascular disease was the most frequent. The majority of patients underwent breast-conserving surgery (79\%) and sentinel lymph node biopsy (95\%) (Table 2). To $94 \%$ of the participants, adjuvant treatment was given. Endocrine therapy was received by $76 \%$ in the control and $79 \%$ the intervention group, respectively. Radiotherapy was administered to $75 \%$ in the control and $83 \%$ in the intervention group, respectively. Adjuvant chemotherapy was given to $26 \%$ in the control compared to $37 \%$ in the intervention group. No severe adverse events related to the intervention were reported. Adherence to the intervention registered as added physical activity ( $>10$ days and $>20$ days before and after surgery) was less than $60 \%$ according to the physical activity diary. Physical activity level measured with SGPALS, at baseline and at the end of the intervention period, showed that $64 \%$ in the intervention and $66 \%$ in the control group did not report any changes in their physical activity level. 
Table 1

Baseline characteristics of study participants

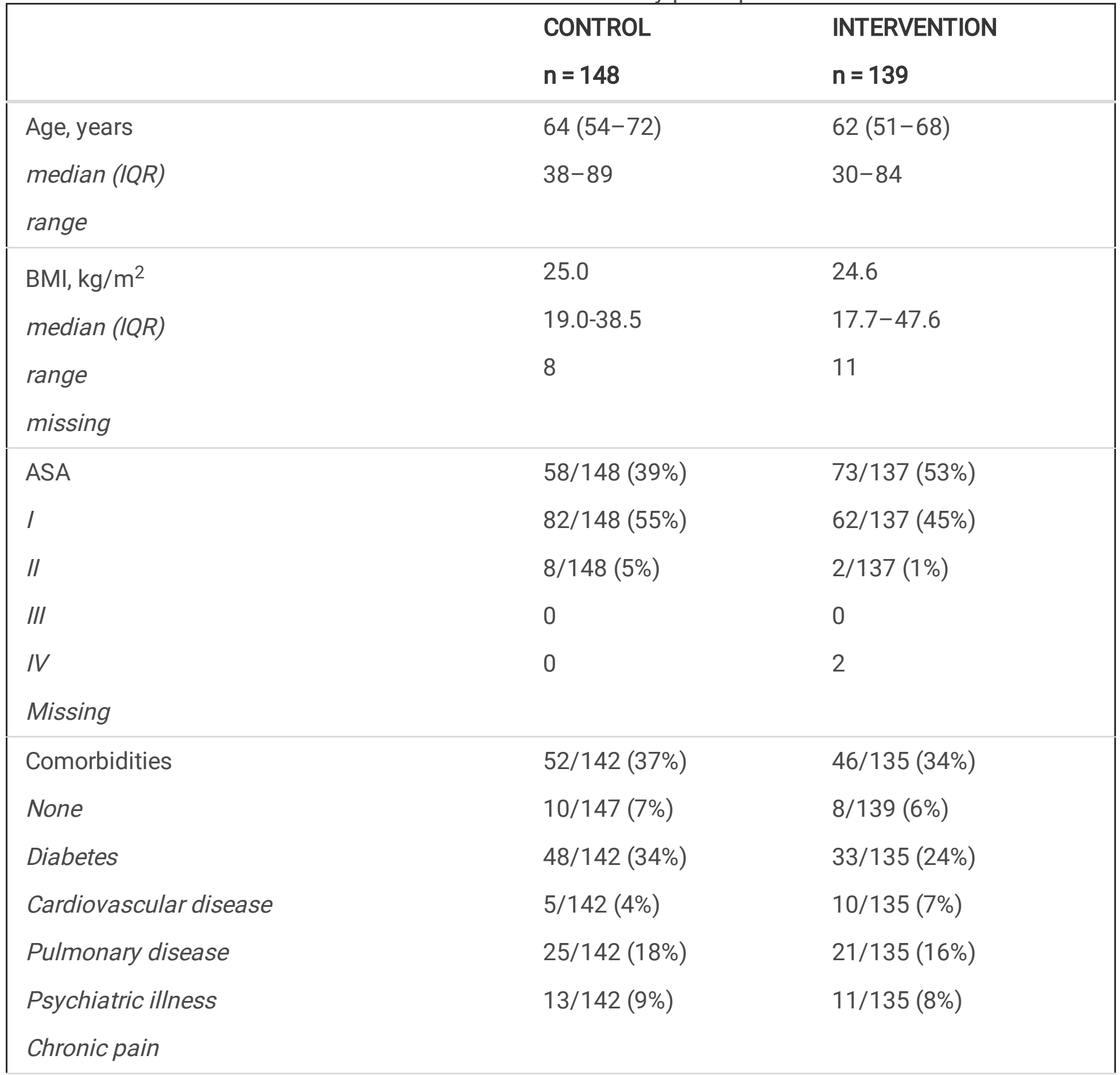

ASA: American Society of Anesthesiologists, BMI: Body Mass Index, SGPALS: Saltin Grimby Physical Activity Level Scale

Valid percent given.

${ }^{1}$ Risk consumption level defined as AUDIT-C-score $\geq 4$

2 Measured using SGPALS at baseline 


\begin{tabular}{|c|c|c|}
\hline & $\begin{array}{l}\text { CONTROL } \\
n=148\end{array}$ & $\begin{array}{l}\text { INTERVENTION } \\
\mathrm{n}=139\end{array}$ \\
\hline Active smoking & $10 / 145(7 \%)$ & $3 / 138(2 \%)$ \\
\hline Yes & 135/145 (93\%) & 135/138 (98\%) \\
\hline No & 3 & 1 \\
\hline Missing & & \\
\hline Alcohol consumption & $94 / 143(66 \%)$ & $93 / 137(68 \%)$ \\
\hline AUDIT-C score $<4$ & $49 / 143(34 \%)$ & $44 / 137(32 \%)$ \\
\hline AUDIT-C score $\geq 4^{1}$ & 5 & 2 \\
\hline Missing & & \\
\hline Physical activity at baseline ${ }^{2}$ & $23 / 147(16 \%)$ & 18/137 (13\%) \\
\hline 1 (inactive) & $97 / 147(66 \%)$ & $85 / 137(62 \%)$ \\
\hline 2 (low) & 27/147 (18\%) & $34 / 137$ (25\%) \\
\hline 3-4 (moderate-vigorous) & 1 & 2 \\
\hline Missing & & \\
\hline Residence & $13 / 147(9 \%)$ & $13 / 138(9 \%)$ \\
\hline Rural & 134/147 (91\%) & 125/138 (91\%) \\
\hline Urban & 1 & 1 \\
\hline Missing & & \\
\hline Educational level & $72 / 147(49 \%)$ & $89 / 138(64 \%)$ \\
\hline University education or higher & $75 / 147(51 \%)$ & $49 / 138(36 \%)$ \\
\hline 12 years or less & 1 & 1 \\
\hline Missing & & \\
\hline $\begin{array}{l}\text { ASA: American Society of Anest } \\
\text { Activity Level Scale }\end{array}$ & Body Mass Ind & : Saltin Grimby Physical \\
\hline Valid percent given. & & \\
\hline${ }^{1}$ Risk consumption level define & $\mathrm{re} \geq 4$ & \\
\hline${ }^{2}$ Measured using SGPALS at $\mathrm{k}$ & & \\
\hline
\end{tabular}


Table 2

Tumour characteristics and treatment

\begin{tabular}{|c|c|c|}
\hline & $\begin{array}{l}\text { CONTROL } \\
n=148\end{array}$ & INTERVENTION n = 139 \\
\hline Type of breast surgery & $114 / 148(77 \%)$ & $113 / 139(81 \%)$ \\
\hline Breast conserving surgery & $34 / 148(23 \%)$ & $26 / 139(19 \%)$ \\
\hline $\begin{array}{l}\text { Mastectomy } \\
\text { Missing }\end{array}$ & 0 & 0 \\
\hline Type of axillary surgery & $142 / 148(96 \%)$ & $131 / 139(94 \%)$ \\
\hline non-ALND ${ }^{1}$ & $6 / 148(4 \%)$ & $8 / 139(6 \%)$ \\
\hline $\begin{array}{l}\text { ALND } \\
\text { Missing }\end{array}$ & 0 & 0 \\
\hline Tumour type & $137 / 148(93 \%)$ & $129 / 139(93 \%)$ \\
\hline Invasive cancer & $11 / 148(7 \%)$ & $10 / 139(7 \%)$ \\
\hline Cancer in-situ & 0 & 0 \\
\hline $\begin{array}{l}\text { Other } \\
\text { Missing }\end{array}$ & 0 & 0 \\
\hline Tumour size (mm), median (IQR) & $16(11-23)$ & $17(11-25)$ \\
\hline Estrogen receptor positive (ER+) & $118 / 148(86 \%)$ & $114 / 139(89 \%)$ \\
\hline Progesterone receptor positive (PR+) & $103 / 148(75 \%)$ & $97 / 139(76 \%)$ \\
\hline Her2-positive (HER2+) & $16 / 148(12 \%)$ & $10 / 139(8 \%)$ \\
\hline Nodal metastasis $(\mathrm{N}+)$ & $26 / 148(19 \%)$ & $36 / 139(27 \%)$ \\
\hline
\end{tabular}

ALND: Axillary Lymph Node Dissection, SGPALS: Saltin Grimby Physical Activity Level Scale

${ }^{1}$ Non-ALND includes Sentinel Lymph Node Biopsy and no axillary surgery 


\begin{tabular}{|lll|}
\hline & CONTROL & INTERVENTION $\mathbf{n}=139$ \\
& $\mathbf{n}=\mathbf{1 4 8}$ & \\
\hline Adjuvant treatment, any & $140 / 148(95 \%)$ & $129 / 137(93 \%)$ \\
Radiotherapy & $111 / 148(75 \%)$ & $113 / 137(83 \%)$ \\
Chemotherapy & $39 / 148(26 \%)$ & $50 / 137(37 \%)$ \\
Endocrine therapy & $113 / 148(76 \%)$ & $108 / 137(79 \%)$ \\
Bisphosphonates & $17 / 148(12 \%)$ & $24 / 137(18 \%)$ \\
Anti-Her-2-therapy & $12 / 148(8 \%)$ & $10 / 137(7 \%)$ \\
Missing & 0 & 2 \\
\hline ALND: Axillary Lymph Node Dissection, SGPALS: Saltin Grimby Physical Activity Level Scale \\
\hline 1 Non-ALND includes Sentinel Lymph Node Biopsy and no axillary surgery \\
\hline
\end{tabular}

FACT-B

At baseline, 4 weeks and 12 months the median FACT-B scores were 116.8, 121.5 and 121.9 in the control group, compared to 117.5, 121.0,119.1 in the control group (Table 4). Comparing the intervention to the control group, the FACT- B score at 4 weeks showed an odds ratio (OR) 0.975 (95\% $\mathrm{Cl} 0.636-1.495)$ and at 12 months OR $0.883(95 \% \mathrm{Cl} 0.581-1.342)$ (Table 3$)$. When adjusted for adjuvant chemotherapy, the odds ratio at 12 months was $0.997(95 \% \mathrm{Cl} 0.654-1.520)$. For the subset of patients who received adjuvant chemotherapy, a significantly lower FACT-B score at 4 weeks and 12 months was seen, with OR 0.418 (95\% $\mathrm{Cl} 0.260-0.670)$ and OR 0.475 (95\% $\mathrm{Cl} 0.300-0.753)$, respectively when compared to those who did not receive chemotherapy (Fig. 2), but with no significant difference based on study group. The FACT-G scores and the breast cancer subscales showed no difference over time or between the study groups (Table 4). FACT-G mean baseline scores were 86.2 for control and 85.7 for intervention (median 87.8 and 87.6 , respectively). 
Table 4

FACT-B score as randomised at baseline, 4 weeks and 12 months

\begin{tabular}{|c|c|c|c|c|c|c|c|c|c|}
\hline & \multirow{2}{*}{\multicolumn{4}{|c|}{$\begin{array}{l}\text { CONTROL } \\
n=148\end{array}$}} & \multirow{2}{*}{\multicolumn{4}{|c|}{$\begin{array}{l}\text { INTERVENTION } \\
\mathrm{n}=139\end{array}$}} \\
\hline & & & & & & & & & \\
\hline & & Mean & Median & $\pm S D$ & Missing & Mean & Median & $\pm S D$ & Missing \\
\hline \multirow{5}{*}{$\begin{array}{l}\text { FACT-B } \\
(0-148)\end{array}$} & Baseline & 115.3 & 116.8 & 16.6 & 11 & 114.7 & 117.5 & 16.7 & 8 \\
\hline & 4 weeks & 117.0 & 121.5 & 18.2 & 8 & 116.3 & 121.0 & 20.0 & 10 \\
\hline & $\begin{array}{l}\text { Change } \\
\text { to } 4 \\
\text { weeks }\end{array}$ & +1.8 & +3.0 & 13.1 & & +2.5 & +2.0 & 12.5 & \\
\hline & $\begin{array}{l}12 \\
\text { months }\end{array}$ & 116.3 & 121.9 & 20.3 & 2 & 115.8 & 119.1 & 19.9 & 3 \\
\hline & $\begin{array}{l}\text { Change } \\
\text { to } 12 \\
\text { months }\end{array}$ & +1.3 & +3.5 & 16.2 & & +0.9 & +2.8 & 14.6 & \\
\hline \multirow{3}{*}{$\begin{array}{l}\text { FACT-G } \\
(0-108)\end{array}$} & Baseline & 86.2 & 87.8 & 13.7 & 7 & 85.7 & 87.6 & 13.8 & 5 \\
\hline & 4 weeks & 88.5 & 93.0 & 14.6 & 8 & 87.2 & 92.0 & 16.4 & 10 \\
\hline & $\begin{array}{l}12 \\
\text { months }\end{array}$ & 88.4 & 93.0 & 16.3 & 0 & 87.8 & 92.0 & 15.6 & 2 \\
\hline \multirow{3}{*}{$\begin{array}{l}\text { Breast } \\
\text { cancer } \\
\text { Subscale } \\
(0-40)\end{array}$} & Baseline & 28.8 & 29.0 & 4.5 & 5 & 28.9 & 30.0 & 4.5 & 5 \\
\hline & 4 weeks & 28.5 & 29.0 & 5.0 & 5 & 29.2 & 30.0 & 4.8 & 8 \\
\hline & $\begin{array}{l}12 \\
\text { months }\end{array}$ & 27.9 & 29.0 & 5.5 & 0 & 28.1 & 29.0 & 5.4 & 1 \\
\hline \multirow{3}{*}{$\begin{array}{l}\text { Physical } \\
\text { well-being } \\
(0-28)\end{array}$} & Baseline & 24.8 & 26.0 & 3.7 & 3 & 24.7 & 25.8 & 3.3 & 1 \\
\hline & 4 weeks & 24.1 & 25.0 & 3.8 & 6 & 24.0 & 26.0 & 4.5 & 8 \\
\hline & $\begin{array}{l}12 \\
\text { months }\end{array}$ & 23.8 & 25.0 & 4.6 & 0 & 23.4 & 24.8 & 4.6 & 1 \\
\hline \multirow{3}{*}{$\begin{array}{l}\text { Emotional } \\
\text { well-being } \\
(0-24)\end{array}$} & Baseline & 16.5 & 17.0 & 4.9 & 2 & 16.8 & 18.0 & 4.8 & 1 \\
\hline & 4 weeks & 19.3 & 20.0 & 4.6 & 6 & 18.7 & 20.0 & 5.2 & 9 \\
\hline & $\begin{array}{l}12 \\
\text { months }\end{array}$ & 20.0 & 21.0 & 4.0 & 1 & 20.1 & 21.0 & 3.9 & 2 \\
\hline
\end{tabular}

FACT-B: Functional assessment of cancer therapy-breast, FACT-G: Functional assessment of cancer therapy- General, TOI: Trial Outcome Index, SD: Standard deviation

${ }^{1}$ Change from baseline 


\begin{tabular}{|c|c|c|c|c|c|c|c|c|c|}
\hline \multirow{3}{*}{$\begin{array}{l}\text { Social } \\
\text { well-being } \\
(0-28)\end{array}$} & Baseline & 24.2 & 25.7 & 3.8 & 5 & 23.7 & 25.0 & 4.4 & 1 \\
\hline & 4 weeks & 24.7 & 25.8 & 3.9 & 6 & 23.9 & 25.0 & 4.3 & 9 \\
\hline & $\begin{array}{l}12 \\
\text { months }\end{array}$ & 23.2 & 24.3 & 5.1 & 2 & 22.8 & 24.0 & 4.6 & 1 \\
\hline \multirow{3}{*}{$\begin{array}{l}\text { Functional } \\
\text { well-being } \\
(0-28)\end{array}$} & Baseline & 20.5 & 21.0 & 5.1 & 2 & 20.4 & 21.0 & 5.5 & 0 \\
\hline & 4 weeks & 20.4 & 21.0 & 5.7 & 6 & 20.8 & 22.0 & 5.6 & 8 \\
\hline & $\begin{array}{l}12 \\
\text { months }\end{array}$ & 21.4 & 22.0 & 5.6 & 0 & 21.6 & 22.5 & 5.3 & 1 \\
\hline \multirow{3}{*}{$\begin{array}{l}\text { FACT-B } \\
\text { TOI }\end{array}$} & Baseline & 74.2 & 76.5 & 10.9 & 8 & 73.9 & 76.0 & 11.3 & 6 \\
\hline & 4 weeks & 73.0 & 75.0 & 12.7 & 7 & 73.9 & 78.0 & 13.4 & 8 \\
\hline & $\begin{array}{l}12 \\
\text { months }\end{array}$ & 73.1 & 77.0 & 13.6 & 0 & 73.0 & 77.0 & 13.8 & 2 \\
\hline \multicolumn{10}{|c|}{$\begin{array}{l}\text { FACT-B: Functional assessment of cancer therapy-breast, FACT-G: Functional assessment of cance } \\
\text { therapy- General, TOl: Trial Outcome Index, SD: Standard deviation }\end{array}$} \\
\hline
\end{tabular}


Table 3

Results for FACT-B total score, EQ-VAS and General QoL question as randomised at 4 weeks and 12 months

\begin{tabular}{|c|c|c|c|}
\hline & \multicolumn{3}{|l|}{$\begin{array}{l}\text { Odds Ratio } \\
\text { Intervention/Control } \\
(95 \% \mathrm{Cl})\end{array}$} \\
\hline & Baseline & 4 weeks & 12 months \\
\hline FACT-B & $1.023(0.676-1.550)$ & $0.975(0.636-1.495)$ & $0.883(0.581-1.342)$ \\
\hline $\begin{array}{l}\text { Crude } \\
\text { Adjusted }^{1}\end{array}$ & & $1.073(0.697-1.651)$ & $0.997(0.654-1.520)$ \\
\hline EQ-VAS & $0.869(0.576-1.312)$ & $1.163(0.760-1.779)$ & $0.817(0.536-1.244)$ \\
\hline $\begin{array}{l}\text { Crude } \\
\text { Adjusted }^{1}\end{array}$ & & $1.254(0.816-1.926)$ & $0.852(0.559-1.300)$ \\
\hline $\begin{array}{l}\text { QoL question² } \\
\text { Crude }\end{array}$ & & $0.91(0.25-3.32)$ & $1.07(0.30-3.86)$ \\
\hline FACT-B: Functio & assessment of cance & erapy-breast, total scc & Cl: Confidence Interva \\
\hline${ }^{1}$ adjusted for a & ant chemotherapy ${ }^{2} \mathrm{D}$ & tomised into "low & nd "high QoL" \\
\hline
\end{tabular}

EQ-VAS

EQ-VAS median score was 80 at all timepoints, and there were no differences seen between the study groups (Table 5). During the active part of the intervention (from baseline to 4 weeks postop), the odds ratio was $1.163(95 \% \mathrm{Cl} 0.760-1.779)$ for the intervention compared to the control group. At 12 months the OR was 0.817 (95\% Cl 0.536-1.244), and adjusted for chemotherapy 0.852 (95\% Cl 0.559-1.300) (Table 3). For all participants regardless of study group, EQ-VAS at 4 weeks had an OR of $0.557(95 \% \mathrm{Cl}$ $0.350-0.886)$, and at 12 months an $\mathrm{OR} 0.656(95 \% \mathrm{Cl} 0.417-1.032)$ for chemotherapy compared to no chemotherapy. 
Table 5

EQ-VAS at baseline, 4 weeks and 12 months, as randomised

\begin{tabular}{|c|c|c|c|c|c|c|}
\hline & CONTROL & & & INTERVENTION & & \\
\hline & $N=148$ & & & $N=139$ & & \\
\hline & $\begin{array}{l}\text { Mean (Min - } \\
\text { Max) }\end{array}$ & Median & $\stackrel{ \pm}{S D}$ & $\begin{array}{l}\text { Mean (Min - } \\
\text { Max) }\end{array}$ & Median & $\stackrel{ \pm}{S D}$ \\
\hline Baseline & $76(5-100)$ & 80 & 18.0 & $73(0-100)$ & 80 & 20.0 \\
\hline 4 weeks & $76(20-100)$ & 80 & 18.0 & $75(20-100)$ & 80 & 19.0 \\
\hline Change $^{1}$ to 4 weeks & $-0.0(-50-40)$ & \pm 0 & 15.8 & $+3.2(-60-90)$ & \pm 0 & 18.2 \\
\hline 12 months & $79(30-100)$ & 80 & 17.0 & $76(27-100)$ & 80 & 19.0 \\
\hline $\begin{array}{l}\text { Change }^{1} \text { to } 12 \\
\text { months }\end{array}$ & $+2.5(-55-45)$ & \pm 0 & 16.0 & $+2.8(-40-98)$ & \pm 0 & 20.2 \\
\hline SD: Standard deviatic & & & & & & \\
\hline${ }^{1}$ from baseline & & & & & & \\
\hline
\end{tabular}

RAND-36

RAND-36 declined in the domains "role limitations due to physical health" and "pain" at 4 weeks postoperatively, with no difference between the study groups. At 12 months participants had to a large extent resumed their QoL (Fig. 3 and Supplementary Table 1).

\section{General QoL question}

Analysis of the dichotomised QoL question, "How would you describe your quality of life the last month?" resulted in no difference between the intervention and control group, neither at 4 weeks (OR $0.91,95 \% \mathrm{Cl}$ $0.25-3.32$ ) nor at 12 months (OR 1.07, 95\% $\mathrm{Cl} 0.30-3.86$ ) (Table 3).

\section{Discussion}

The results from this randomized trial examining the effect of moderate physical activity as prehabilitation in women undergoing breast cancer surgery did not show effects on QoL at 4 weeks or 12 months after surgery. Previous studies on QoL during adjuvant treatment [15] have primarily investigated effects following supervised, high intensity exercise interventions for a longer period of time [11]. Even with such intense exercise interventions, significant improvements in quality of life have not been reported [11]. This may in part be explained by a high baseline level of QoL in breast cancer patients, as also seen in our trial, and difficulties to detect and/or discriminate improvements from this level. The aim of our trial was to investigate the effect of a simple non-supervised intervention, in keeping with national and international recommendations regarding physical activity [25]. The intervention was chosen, 
assumed to be easily implementable and with slight impact on the care pathway for breast cancer treatment.

The FACT-G score in our trial cohort revealed a higher level of QoL, with a mean baseline score of 86, compared to 77 in the normative data for the general Swedish female population sample (pro-rated mean FACT-GP scores) [26]. The FACT-G minimally important difference (MID) is considered to be approximately 5-6 in a breast cancer population, with a MID 7-8 for the total FACT-B score [27]. The higher FACT-G score in our sample of breast cancer patients could suggest a selection bias, where individuals with lower QoL declined participation. Another possible explanation is the difference in age distribution in our study sample (mean 62 years) compared to the population sample (mean 49 years), as a higher age was positively correlated to higher FACT-GP score. Moreover, the FACT-G and FACT-B scores we present are similar to previously published results for breast cancer patients [28-30]. Over time, the FACT-B scores were stable regardless of study group and treatment factors, except for the subgroup of patient receiving adjuvant chemotherapy, where a significant decline was seen. Interestingly, this was not only seen at 12 months but also at 4 weeks, when the participants had not yet started their adjuvant chemotherapy but had gained information about the projected start of treatment.

EQ-VAS median score was stable regardless of study group and time for assessment and all changes seen in mean scores were less than the MID of 8 for EQ-VAS [31]. RAND-36 showed a temporary decline in the domains "Pain" and "Role limitations due to physical health" at 4 weeks, these changes were not seen at 12 months where participants had resumed their QoL. Interestingly, the domain "Emotional well-being" showed even better results at 12 months compared to baseline, possibly as a result of improved adaptive strategies and response shift over time. The domain "General health" improved during the active intervention period at 4 weeks after surgery, but at 12 months returned to baseline.

The consistency in FACT-B and EQ-VAS score from baseline to 4 weeks after surgery could indicate an inability of the instruments to encompass or discriminate changes resulting from the surgical insult, or that breast cancer diagnosis and surgery alone in fact has low impact on QoL. A significant difference was only seen for patients receiving adjuvant chemotherapy, compared to patients not receiving adjuvant chemotherapy, suggesting that this is a subgroup of patients that may benefit more from interventions aimed at improving QoL.

The strengths of the current study include the randomized controlled design, the use of several validated QoL instruments, both generic and disease specific, as well as both short- and long-term follow-up. Limitations include the lack of objective measures of physical activity, regarding type, duration and/or intensity of physical activity. Low adherence to the intervention, confine the effects of this non-supervised intervention and point to the draw-backs of recommendations regarding exercise, in line with previous studies [11, 32]. Our results, in accordance with previous findings seem to suggest the need for improved strategies and additional support in order to achieve the recommended physical activity level for patients with breast cancer. 


\section{Conclusion}

Based on the results from these and previously presented outcomes of this trial we cannot advocate for prehabilitation including a recommendation of physical activity into guidelines for patients awaiting surgery for breast cancer.

\section{Abbreviations}

ASA American Society of Anesthesiologists

AUDIT-C Alcohol Use Disorders Identification Test

BMI Body Mass Index

Cl Confidence Interval

EQ-VAS EuroQol- visual analogue scale

FACT-B Functional Assessment of Cancer Therapy-Breast Cancer

FACT-G Functional Assessment of Cancer Therapy-General

FACT-GP Functional Assessment of Cancer Therapy-General Population

MID Minimally Important Difference

OR Odds ratio

PRO Patient-reported outcome

QoL Quality of life

RAND-36 RAND 36-Item Health Survey 1.0

SGPALS Saltin Grimby Physical Activity Level Scale

SD Standard deviation

TOI Trial Outcome Index

\section{Declarations}

Funding This study was funded by Sahlgrenska University Hospital (ALFGBG-4307771, ALFGBG-718221), AFA Insurance (150072), The Swedish Cancer Society (CAN 2016/362, 2020/ 19 0303), The Gothenburg Medical Society (GLS 779001, GLS 879101), Lions Cancer Research Fund of Western Sweden (LCV2018:28), Anna-Lisa and Bror Björnssons Foundation and Knut and Alice Wallenberg Foundation. 
Conflict of Interest The authors declare that they have no conflicts of interest.

Availability of data and material The datasets generated during and/or analysed during the current study are available from the corresponding author on reasonable request.

Code availability Not applicable

Authors' contributions All authors contributed to the study conception and design. Material preparation, data collection and analysis were performed by Jenny Heiman, Eva Haglind and Roger Olofsson Bagge. The first draft of the manuscript was written by Jenny Heiman and all authors commented on previous versions of the manuscript. All authors read and approved the final manuscript.

Ethical approval All procedures performed involving human participants were in accordance with the ethical standards of the institutional and national research committee (Regional Ethical Review Board in Gothenburg, Sweden, registration numbers: 522-15, T1152-16, T700-17, T160-18) and with the 1964 Helsinki declaration with amendments.

Consent to participate Informed consent was obtained from all individual participants included in the trial.

Consent for publication Not applicable

\section{Acknowledgements}

We extend our gratitude to the participants in the PhysSURG-B trial, the physiotherapists involved in the intervention, as well as research nurses and all personnel involved in conducting the trial at the including hospitals.

\section{References}

1. Global Cancer Observatory: Cancer Today [Available from: https://gco.iarc.fr/today]

2. Fenlon D, Powers C, Simmonds P, Clough J, Addington-Hall J: The JACS prospective cohort study of newly diagnosed women with breast cancer investigating joint and muscle pain, aches, and stiffness: pain and quality of life after primary surgery and before adjuvant treatment. BMC Cancer 2014, 14:467.

3. Sprangers MA: Disregarding clinical trial-based patient-reported outcomes is unwarranted: Five advances to substantiate the scientific stringency of quality-of-life measurement. Acta Onco/ 2010, 49(2):155-163.

4. Sprangers MA: Quality-of-life assessment in oncology. Achievements and challenges. Acta Oncol 2002, 41(3):229-237.

5. Testa MA, Simonson DC: Assessment of quality-of-life outcomes. N Engl J Med 1996, 334(13):835840. 
6. Ballard-Barbash R, Friedenreich CM, Courneya KS, Siddiqi SM, McTiernan A, Alfano CM: Physical activity, biomarkers, and disease outcomes in cancer survivors: a systematic review. J Natl Cancer Inst 2012, 104(11):815-840.

7. Ogunleye AA, Holmes MD: Physical activity and breast cancer survival. Breast Cancer Res 2009, 11(5):106.

8. Holmes MD, Chen WY, Feskanich D, Kroenke CH, Colditz GA: Physical activity and survival after breast cancer diagnosis. JAMA 2005, 293(20):2479-2486.

9. Mijwel S, Backman M, Bolam KA, Jervaeus A, Sundberg CJ, Margolin S, Browall M, Rundqvist H, Wengstrom $Y$ : Adding high-intensity interval training to conventional training modalities: optimizing health-related outcomes during chemotherapy for breast cancer: the OptiTrain randomized controlled trial. Breast Cancer Res Treat 2018, 168(1):79-93.

10. Juvet LK, Thune I, Elvsaas IKO, Fors EA, Lundgren S, Bertheussen G, Leivseth G, Oldervoll LM: The effect of exercise on fatigue and physical functioning in breast cancer patients during and after treatment and at 6 months follow-up: A meta-analysis. Breast 2017, 33:166-177.

11. Bolam KA, Mijwel S, Rundqvist $\mathrm{H}$, Wengstrom Y: Two-year follow-up of the OptiTrain randomised controlled exercise trial. Breast Cancer Res Treat 2019, 175(3):637-648.

12. Mishra SI, Scherer RW, Snyder C, Geigle PM, Berlanstein DR, Topaloglu O: Exercise interventions on health-related quality of life for people with cancer during active treatment. Cochrane Database Syst Rev 2012(8):CD008465.

13. Baglia ML, Lin IH, Cartmel B, Sanft T, Ligibel J, Hershman DL, Harrigan M, Ferrucci LM, Li FY, Irwin ML: Endocrine-related quality of life in a randomized trial of exercise on aromatase inhibitor-induced arthralgias in breast cancer survivors. Cancer 2019.

14. Dieli-Conwright CM, Courneya KS, Demark-Wahnefried W, Sami N, Lee K, Sweeney FC, Stewart C, Buchanan TA, Spicer D, Tripathy D et al: Aerobic and resistance exercise improves physical fitness, bone health, and quality of life in overweight and obese breast cancer survivors: a randomized controlled trial. Breast Cancer Res 2018, 20(1):124.

15. Steindorf K, Schmidt ME, Klassen O, Ulrich CM, Oelmann J, Habermann N, Beckhove P, Owen R, Debus $\mathrm{J}$, Wiskemann $\mathrm{J}$ et al: Randomized, controlled trial of resistance training in breast cancer patients receiving adjuvant radiotherapy: results on cancer-related fatigue and quality of life. Ann Oncol 2014, 25(11):2237-2243.

16. Heiman J, Onerup A, Wessman C, Haglind E, Olofsson Bagge R: Recovery after breast cancer surgery following recommended pre and postoperative physical activity: (PhysSURG-B) randomized clinical trial. Br J Surg 2020.

17. Saltin B, Grimby G: Physiological analysis of middle-aged and old former athletes. Comparison with still active athletes of the same ages. Circulation 1968, 38(6):1104-1115.

18. Brady MJ, Cella DF, Mo F, Bonomi AE, Tulsky DS, Lloyd SR, Deasy S, Cobleigh M, Shiomoto G: Reliability and validity of the Functional Assessment of Cancer Therapy-Breast quality-of-life instrument. J Clin Oncol 1997, 15(3):974-986. 
19. Garratt AM, Ruta DA, Abdalla MI, Buckingham JK, Russell IT: The SF36 health survey questionnaire: an outcome measure suitable for routine use within the NHS?BMJ 1993, 306(6890):1440-1444.

20. EuroQol G: EuroQol-a new facility for the measurement of health-related quality of life. Health Policy 1990, 16(3):199-208.

21. Bock D, Angenete E, Bjartell A, Carlsson S, Steineck G, Stranne J, Thorsteinsdottir T, Wiklund P, Haglind E: Habits and self-assessed quality of life, negative intrusive thoughts and depressed mood in patients with prostate cancer: a longitudinal study. Scand J Urol 2017, 51(5):353-359.

22. Steineck G, Bergmark K, Henningsohn L, al-Abany M, Dickman PW, Helgason A: Symptom documentation in cancer survivors as a basis for therapy modifications. Acta Oncol 2002, 41(3):244252 .

23. Johansson E, Steineck G, Holmberg L, Johansson JE, Nyberg T, Ruutu M, Bill-Axelson A, Investigators S-: Long-term quality-of-life outcomes after radical prostatectomy or watchful waiting: the Scandinavian Prostate Cancer Group-4 randomised trial. Lancet Oncol 2011, 12(9):891-899.

24. Harrell FE, Jr: Regression Modeling Strategies With Applications to Linear Models, Logistic and Ordinal Regression, and Survival Analysis, Second edn: Springer, Cham; 2015.

25. Bull FC, Al-Ansari SS, Biddle S, Borodulin K, Buman MP, Cardon G, Carty C, Chaput JP, Chastin S, Chou $\mathrm{R}$ et al: World Health Organization 2020 guidelines on physical activity and sedentary behaviour. $\mathrm{Br} \mathrm{J}$ Sports Med 2020, 54(24):1451-1462.

26. Lindqvist Bagge AS, Carlander A, Fahlke C, Olofsson Bagge R: Health-related quality of life (FACT-GP) in Sweden. Health Qual Life Outcomes 2020, 18(1):172.

27. Eton DT, Cella D, Yost KJ, Yount SE, Peterman AH, Neuberg DS, Sledge GW, Wood WC: A combination of distribution- and anchor-based approaches determined minimally important differences (MIDs) for four endpoints in a breast cancer scale. J Clin Epidemiol 2004, 57(9):898-910.

28. Rogers LQ, Hopkins-Price P, Vicari S, Pamenter R, Courneya KS, Markwell S, Verhulst S, Hoelzer K, Naritoku $C$, Jones $L$ et al: A randomized trial to increase physical activity in breast cancer survivors. Med Sci Sports Exerc 2009, 41(4):935-946.

29. Vallance JK, Courneya KS, Plotnikoff RC, Yasui Y, Mackey JR: Randomized controlled trial of the effects of print materials and step pedometers on physical activity and quality of life in breast cancer survivors. J Clin Oncol 2007, 25(17):2352-2359.

30. Shaitelman SF, Schlembach PJ, Arzu I, Ballo M, Bloom ES, Buchholz D, Chronowski GM, Dvorak T, Grade E, Hoffman KE et al: Acute and Short-term Toxic Effects of Conventionally Fractionated vs Hypofractionated Whole-Breast Irradiation: A Randomized Clinical Trial. JAMA Oncol 2015, 1(7):931941.

31. Pickard AS, Neary MP, Cella D: Estimation of minimally important differences in EQ-5D utility and VAS scores in cancer. Health Qual Life Outcomes 2007, 5:70.

32. Schmitz KH, Courneya KS, Matthews C, Demark-Wahnefried W, Galvao DA, Pinto BM, Irwin ML, Wolin $\mathrm{KY}$, Segal RJ, Lucia A et al: American College of Sports Medicine roundtable on exercise guidelines for cancer survivors. Med Sci Sports Exerc 2010, 42(7):1409-1426. 

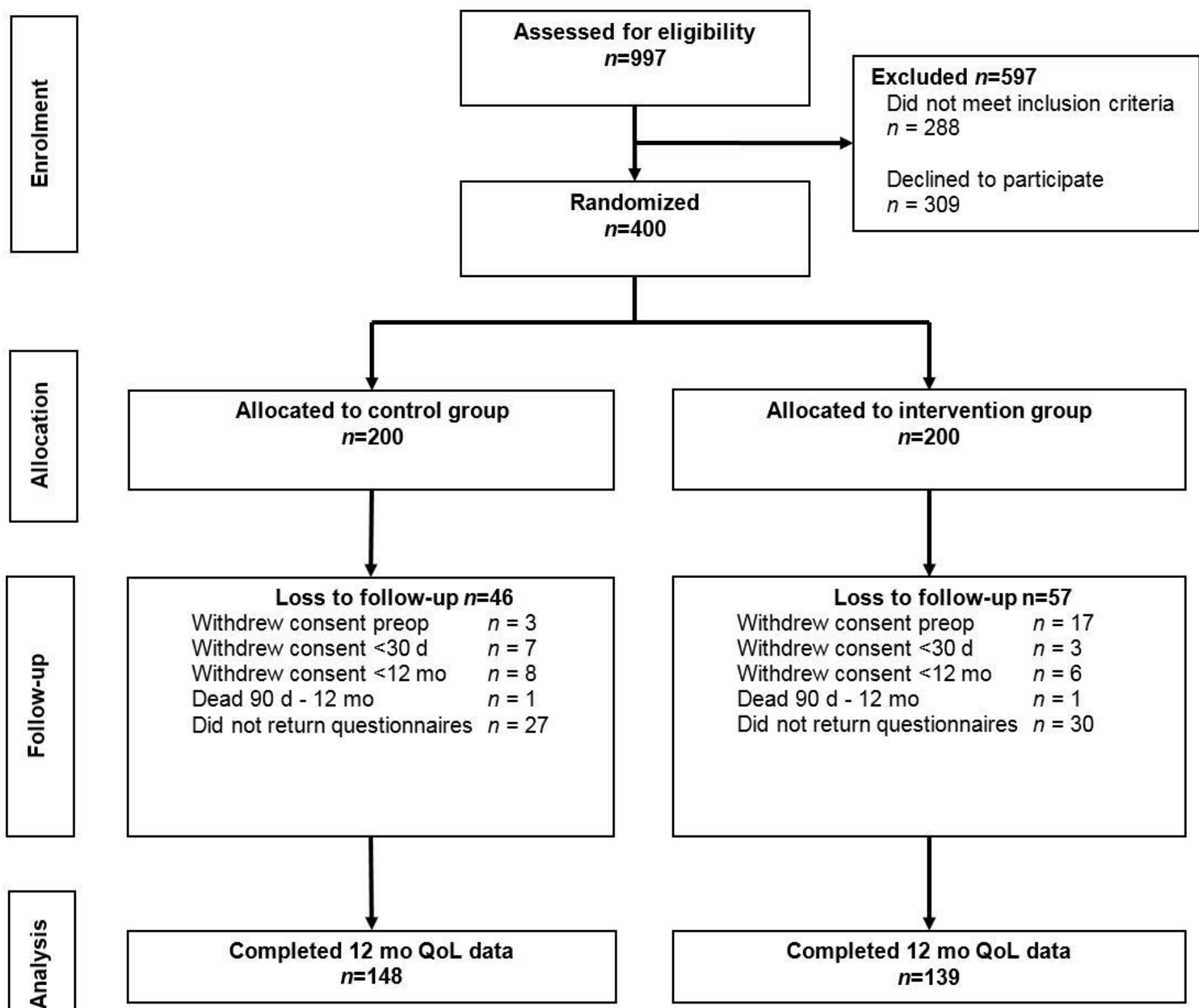

Figure 1

CONSORT flow diagram for the PhysSURG-B trial At baseline, 340/380 patients (90\%) returned the baseline questionnaire. At 4 weeks after surgery, 370/400 patients (93\%) remained in the trial, of these $318 / 370$ (86 \%) returned the 4 week questionnaire, $89 \%$ in control and $83 \%$ in intervention. At 12 months, the questionnaire was returned by $297 / 354$ patients ( $84 \%), 154 / 181(85 \%)$ in control and $143 / 173(83 \%)$ in intervention. 


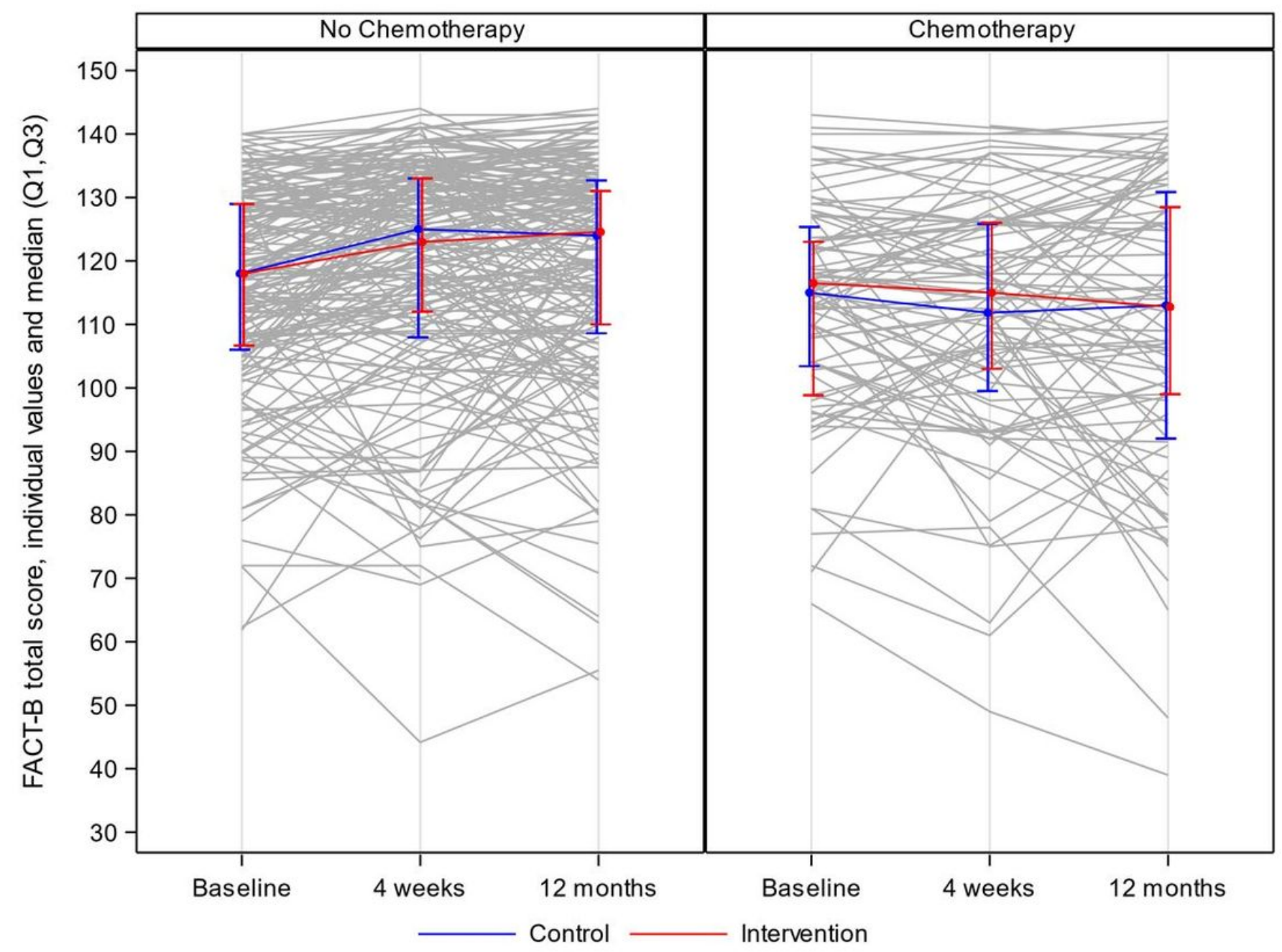

Figure 2

FACT-B spaghetti plot at baseline, 4 weeks and 12 months for patients receiving chemotherapy compared to no chemotherapy. Participants (both intervention and control) with adjuvant chemotherapy had significantly lower FACT-B total score, with OR 0.418 (95\% Cl 0.260-0.670) at 4 weeks and OR 0.475 (95\% $\mathrm{Cl}$ 0.300-0.753) at 12 months, compared to no chemotherapy. 


\section{RAND-36 Difference from baseline}

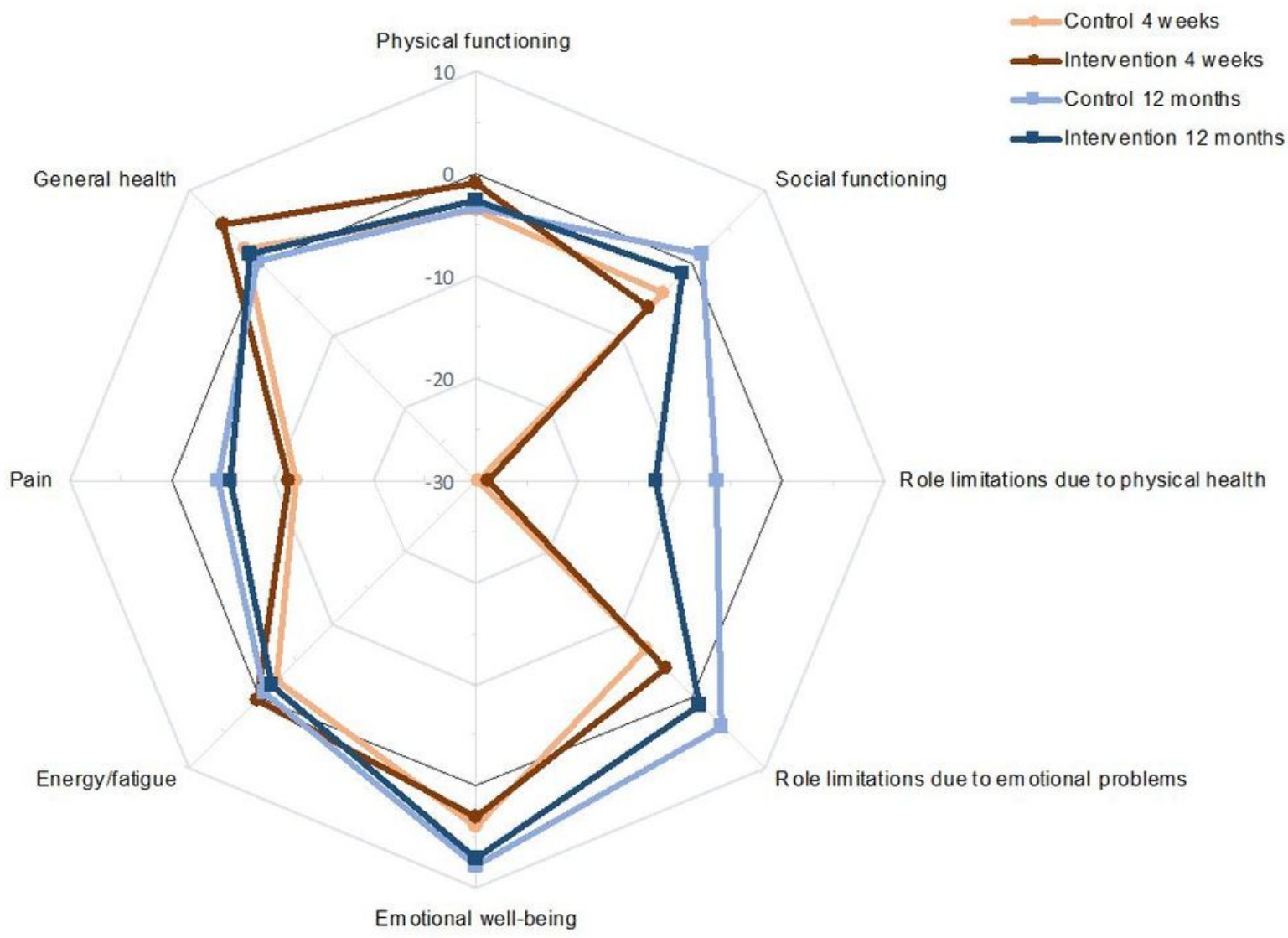

Figure 3

Difference from baseline to 4 weeks and 12 months as randomised for the eight domains of RAND-36.

\section{Supplementary Files}

This is a list of supplementary files associated with this preprint. Click to download.

- SupplementaryTable1.docx 